\title{
Challenges in Cost-Effectiveness Analysis Modelling of HPV Vaccines in Low- and Middle-Income Countries: A Systematic Review and Practice Recommendations
}

\author{
Obinna I. Ekwunife ${ }^{1,2} \cdot$ James F. O'Mahony ${ }^{3}$ Andreas Gerber Grote ${ }^{4,6} \cdot$ \\ Christoph Mosch $^{5} \cdot$ Tatjana Paeck $^{7} \cdot$ Stefan K. Lhachimi ${ }^{1,7}$
}

Published online: 16 September 2016

(c) The Author(s) 2016. This article is published with open access at Springerlink.com

\begin{abstract}
Background Low- and middle-income countries (LMICs) face a number of challenges in implementing cervical cancer prevention programmes that do not apply in highincome countries.

Objective This review assessed how context-specific challenges of implementing cervical cancer prevention strategies in LMICs were accounted for in existing costeffectiveness analysis (CEA) models of human papillomavirus (HPV) vaccination.

Methods The databases of MEDLINE, EMBASE, NHS Economic Evaluation Database, EconLit, Web of Science, and the Center for the Evaluation of Value and Risk in Health (CEA) Registry were searched for studies published from 2006 to 2015. A descriptive, narrative, and interpretative synthesis of data was undertaken.
\end{abstract}

Obinna I. Ekwunife

ekwunife@uni-bremen.de; oi.ekwunife@unizik.edu.ng

James F. O’Mahony

jfomahon@tcd.ie

Andreas Gerber Grote

mail@andreas.gerber.de

Christoph Mosch

Christoph.Mosch@uni-wh.de

Tatjana Paeck

paeck@bips.uni-bremen.de

Stefan K. Lhachimi

Stefan.Lhachimi@uni-bremen.de

1 Collaborative Research Group for Evidence-Based Public Health, Department of Prevention and Evaluation, Leibniz Institute for Prevention Research and Epidemiology, BIPS/ University of Bremen, Achterstr. 30, 28359 Bremen, Germany
Results Of the 33 studies included in the review, the majority acknowledged cost per vaccinated girl (CVG) $(26$ studies) and vaccine coverage rate (21 studies) as particular challenges for LMICs, while nine studies identified screening coverage rate as a challenge. Most of the studies estimated CVG as a composite of different cost items. However, the basis for the items within this composite cost was unclear. The majority used an assumption rather than an observed rate to represent screening and vaccination coverage rates. CVG, vaccine coverage and screening coverage were shown by some studies through sensitivity analyses to reverse the conclusions regarding cost-effectiveness, thereby significantly affecting policy recommendations.

Conclusions While many studies recognized aspects of the particular challenges of HPV vaccination in LMICs, greater efforts need to be made in adapting models to

2 Department of Clinical Pharmacy and Pharmacy

Management, Nnamdi Azikiwe University, Awka, Nigeria

3 Centre for Health Policy and Management, School of Medicine, Trinity College Dublin, Dublin, Ireland

4 Institute for Health Economics and Clinical Epidemiology, University of Cologne, Cologne, Germany

5 Institute for Research in Operative Medicine (IFOM), Universität Witten/Herdecke, Witten, Germany

6 Department of Health, ZHAW, Winterthur, Switzerland

7 Institute for Public Health and Nursing Research, IPP, Health Sciences Bremen, University of Bremen, Bremen, Germany 
account for these challenges. These include adapting costings of HPV vaccine delivery from other countries, learning from the outcomes of cervical cancer screening programmes in the same geographical region, and taking into account the country's previous experience with other vaccination programmes.

\section{Key Points for Decision Makers}

Cost per vaccinated girl, vaccine coverage and screening coverage are highly uncertain parameters in model-based cost-effectiveness analysis (CEA) of human papillomavirus (HPV) vaccines in low- and middle-income countries.

These uncertain parameters matter as they can reverse the conclusions regarding cost-effectiveness made by a CEA, thereby altering the resulting policy choice.

More precise parameters could be obtained by adapting costings of HPV vaccine delivery conducted for other countries, observing the outcomes of cervical cancer screening programmes in the same geographical region, and taking into account the country's previous experience with other vaccination programmes.

\section{Introduction}

The worldwide annual absolute incidence and mortality of cervical cancer in 2012 was 528,000 and 266,000, respectively, making it the fourth most common cancer affecting women [1]. The global burden of mortality from the disease falls disproportionately on low- and middleincome countries (LMICs), which account for approximately $90 \%$ of cervical cancer deaths [1]. Cervical cancer and its precursor lesions can be detected by screening women with screening technologies such as cytology-based screening, visual inspection with acetic acid (VIA) and the human papillomavirus (HPV) DNA test [2] and thus treated at an earlier stage, thereby improving survival. The disease can also be prevented by vaccination against oncogenic HPV strains [2]. While screening and vaccination programmes have been effective in reducing cervical cancer incidence in developed countries, LMICs have had difficulties in implementing them [3,4].

In 2009, the World Health Organization (WHO) recommended routine HPV vaccination for girls on the condition that vaccination was found to be cost-effective when assessed in the country or region in question [5]. A comprehensive cervical cancer prevention and control strategy should include three levels of activity [2]: primary prevention, involving HPV vaccination of girls (and boys if affordable) between 9 and 13 years; secondary prevention, in which women 30 years of age or older are "screened and treated" with low-cost technologies especially for low-resource settings; and tertiary prevention, in which all women with invasive cancer are to be treated as necessary.

Cost-effectiveness analysis (CEA) is a widely applied method used to identify which health care interventions deliver the best value for money. It identifies the most effective health care intervention strategy while accounting for the opportunity cost of other services foregone. A comprehensive CEA of cervical cancer prevention involves comparison of alternative prevention strategies, including various screening intensities and/or vaccination. Numerous studies assessing the cost-effectiveness of HPV vaccination have been published for high-, middle- and low-income countries. These typically employ decision analytic models as many of the relevant outcomes will occur over periods too long to practically assess within trials. CEAs of HPV vaccination for LMICs often use and adapt decision analytic models employed by studies conducted in high-income countries.

The challenges encountered by LMICs in implementing cervical cancer prevention strategies are relevant for CEAs of such programmes. Existing infrastructure may not have the capacity to support adolescent vaccine delivery requiring a substantial set-up cost [6, 7]. Adolescent vaccine delivery requires the following: (1) micro-planning to assess issues of accessibility, geography, population movements and cultural characteristics; (2) social mobilization/information, education and communication to increase vaccine awareness; (3) higher cold chain requirements for delivery outside health facilities compared with childhood immunization; and (4) greater service delivery costs compared with childhood immunization [8]. Many LMICs lack the political commitment to maintain vaccination infrastructure in the face of competing priorities [9]. Additionally, weak surveillance capability problems also impact negatively on HPV immunization coverage. Reaching girls who are not enrolled in schools is also a considerable challenge [10]. Societal and cultural issues related to poverty, illiteracy, religious taboos, superstition, the influence of traditional/religious healers, and an overemphasis on curative rather than preventive medicine are all obstacles for effective vaccination [9]. For instance, possibility of avoidance in vaccination participation by certain groups due to cultural and religious sensitivities has been suggested, as the vaccines are offered to prevent a sexually transmitted disease in young girls [6]. 
As with vaccination, many LMICs lack resources to establish systematic cervical cancer screening programmes [10]. Routine screening is underutilized in LMICs because of a lack of public health policy prioritization, professional and general education, and media awareness, under-developed clinical facilities, inadequate financial resources and, most crucially, insufficient capacity for effective follow-up treatment of identified lesions [11]. As such, routine screening is often unsustainable in many LMICs. Even when achievable, screening programmes may only achieve very low coverage. As an illustration, cervical cancer screening coverage is less than $20 \%$ in South Africa [12] and about $8.7 \%$ in Nigeria [13]. In Latin America, Costa Rica, Bolivia, El Salvador, Nicaragua and Panama have coverage rates ranging from 10 to $20 \%$ [14].

These challenges in implementing and maintaining a comprehensive cervical cancer prevention strategy make it difficult to anticipate what programme coverage rates and cost of vaccination might be realised. Both are crucial parameters in most decision analytic models of HPV vaccination as they can determine whether vaccination is costeffective or not. Accordingly, such analyses need to account for these distinct challenges, which do not apply to high-income countries to the same extent, if the appropriate policy advice is to be given.

Systematic reviews of CEAs of HPV vaccination in LMICs have been published previously $[15,16]$. Although these previous works investigated how CEA results are affected by model characteristics and underlying assumptions, they did not systematically consider how the contextspecific challenges posed by LMICs affect the results and policy recommendations. Our review adds new insights by assessing how context-specific challenges in implementing and maintaining cervical cancer prevention and control strategies in LMICs were accounted for in CEA models of HPV vaccination. This review specifically examines the following questions: (1) Does the existing HPV vaccination cost-effectiveness literature acknowledge the particular challenges of LMICs? (2) How were the LMIC-particular challenges accommodated in the models? (3) Is the uncertainty among the parameters that are particularly sensitive to the implementation challenges in LMICs so large that the policy recommendations are affected?

\section{Methods}

\subsection{Eligibility Criteria}

This systematic review was conducted in accordance with a protocol registered with the International Prospective Register of Systematic Reviews (PROSPERO: CRD42015017870) [7]. The review focused on studies on CEA of HPV vaccination using decision analytic models [17]. Other inclusion criteria were as follows: studies that considered the cost-effectiveness of HPV vaccination and reported costs and health effects in terms of quality-adjusted life years (QALYs), disability-adjusted life years (DALYs) or life years gained (LYGs); studies that were set in LMICs according to the World Bank classification [18]; selected articles included both original research papers and reviews; studies published in any language; and studies published since the first licensed vaccine in 2006.

\subsection{Search Strategy and Data Extraction}

MEDLINE (via PubMed), EMBASE, NHS Economic Evaluation Database (NHS EED), EconLit, Web of Science, and the Center for the Evaluation of Value and Risk in Health (CEA) Registry were searched for eligible studies on 15 March 2015. Cochrane Reviews, Cochrane DARE, and Cochrane Health Technology Assessment Databases were also searched for existing systematic reviews on the cost-effectiveness of HPV vaccines. Reviews were included to ensure that no study was omitted.

Details of the search strategy used are presented in Appendix 1 (Table 4). The reference lists of all relevant articles identified during the search were reviewed to identify further studies that were missed. Furthermore, the PubMed 'related articles' were used to search for eligible studies. Both screened titles or abstracts and retrieved articles were managed using EndNote X7.3. Titles and abstracts were screened for inclusion independently by $\mathrm{OE}$ and TP using the eligibility criteria. The opinion of a third reviewer (SL) was sought to arrive at a consensus in cases where there was disagreement on a study for inclusion. Data were extracted from included studies using a predefined data extraction spreadsheet as per protocol [7].

\subsection{Data Items}

Characteristics of included studies were extracted (Appendix 2, Table 5). Context-specific challenges with vaccination and screening parameters were identified. Furthermore, the accommodation of the context-specific challenges in the decision analytic model and their influence on CEA estimates were examined and reported.

\subsection{Quality Assessment}

The included studies were assessed using the Consolidated Health Economic Evaluation Reporting Standards (CHEERS) statement [19]. CHEERS is a 23-item checklist developed to aid transparency and clarity in the reporting of economic evaluations. One point was allotted if a study fulfilled each of the CHEERS statement items. Only those 
items applicable to the studies were considered. For instance, item 12-measurement and valuation of preference based outcomes-was omitted for some studies since it is not applicable to all the studies.

\section{Results}

\subsection{Search Results}

Figure 1 shows a flow diagram of the study selection process. The database searches yielded a total of 6151 abstracts/titles and 3585 abstracts/titles after removal of duplicates. Another five studies were identified from existing reviews. After screening of abstract and titles, 33 articles were retrieved for review [20-52] (Appendix 2). The quality assessment score for each study is shown in the final column of Table 5. The included studies conformed to most of the CHEERS items (i.e. $\geq 19$ points in a 22-point scale), indicating acceptable overall reporting quality.

\subsection{Context-Specific Uncertain Parameters}

The majority of the studies (26) acknowledged cost per vaccinated girl (CVG) as a challenge. $\mathrm{CVG}$ was reported as unknown, and thus analyses had to simulate an assumed CVG [21-24, 26-29, 31, 33, 34, 37-46, 48-52]. Twenty-one studies identified vaccine coverage as a challenge
[20, 24-26, 28-31, 33, 35, 36, 40-43, 46, 48-52], especially as there was no past experience of HPV vaccination programmes in the countries of study. Nine studies identified screening coverage as a challenge [25, 26, 30, 31, 33, 34, 42, 43, 46, 49]. Of these nine studies, two applied the coverage of current cervical cancer screening practice in a base case analysis and assessed the impact of enhanced screening coverage on the policy recommendation in the sensitivity analysis [31, 46]. The other seven studies assumed an organized national cervical screening scenario [25, 26, 30, 34, 42, 43, 49]. Other challenges acknowledged by studies were possible interruption of screening programme due to scarcity of funds [20]; patients lost to follow-up after screening or failure to treat screen-detected disease [27, 30]; the prevalence and cost of treating genital warts [35]; and uncertainty regarding sexual mixing parameters [51].

\subsection{Accommodation of Context-Specific Parameters}

Most of the studies estimated CVG as an approximate composite value that included vaccine cost, wastage, freight and supplies, administration, immunization support and programme costs $[22,25,28-30,32,40-45,48,51,52]$. It was not clear how the composite cost items were derived in these studies. The composite costs were often varied over a wide range of values in sensitivity analysis. Another study used only the market prices of HPV vaccine in the base case analysis and considered other vaccine delivery associated
Fig. 1 Flow diagram of study selection process

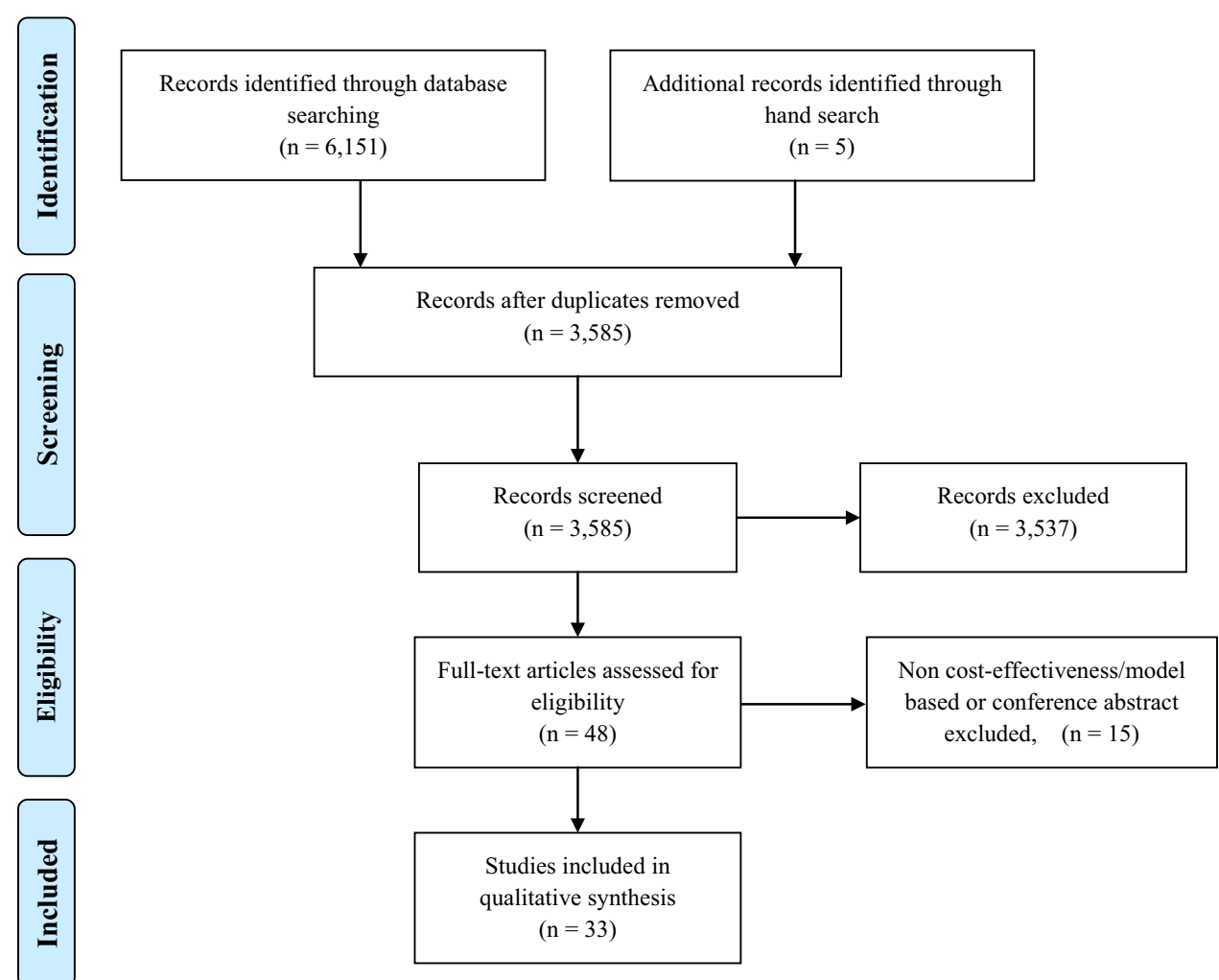


costs (transportation, storage, product losses) in the sensitivity analysis [20]. The primary rationale given for the ranges of $\mathrm{CVG}$ or vaccine price used in the sensitivity analysis was to determine a threshold price at which the vaccine would be cost-effective.

All the studies where a vaccine coverage parameter $[26,35,42,47]$ or a screening coverage parameter $[42,46]$ was influential on the policy recommendation used an assumption rather than an observed rate used in similar context or pilot study. The assumed screening coverage ranged from 20 to $100 \%$, with $70 \%$ being the most commonly used in the base case analysis. Similarly, the assumed vaccine coverage rates ranged from 0 to $100 \%$, with $70 \%$ being the most commonly used in the base case analysis. There was no rationale stated for the assumed screening or vaccine coverage levels in these studies. Details are shown in Table 1.

\subsection{Influence of Context-Specific Parameters on Policy Recommendation}

Effect of sensitivity analysis on the policy recommendation is shown in Table 2. From the base case analysis, 25 out of the 33 studies recommended HPV vaccination (denoted by a positive [+] sign), while four studies recommended cervical cancer screening $[20,34,46]$ or the current scenario of no preventive intervention [38] (denoted by a negative [-] sign). Eighteen studies found that uncertainty surrounding CVG within the ranges they considered was sufficiently large to change the policy recommendation from acceptance to rejection or vice versa [20, 22, 25, 27-30, 32, 34, 40, 41, 46-48, 50, 52]. Four studies found uncertainty surrounding vaccine coverage rate to be influential on the policy recommendation $[26,35,42,47]$. Two studies found uncertainty regarding screening coverage rates to be influential on the policy recommendation $[42,46]$. Some studies conducted sensitivity analyses for these context-specific parameters, but did not report the results. Specifically, one study did not report for CVG [37], seven studies did not report for screening coverage rate [29, 30, 32, 41, 43, 45, 47], and six studies did not report for vaccine coverage rate [28-30, 32, 41, 43].

\section{Discussion and Recommendations}

This review identified parameters that were particularly context-specific in CEAs of HPV vaccination and assessed how they were accounted for in analyses in LMICs. This review showed that the majority of the decision analytic models of HPV vaccination did explicitly note that there were LMIC-specific challenges. Although most of the studies acknowledged specific challenges, the review also showed that there is scope for improvement in how these are managed. This section discusses the findings of the review and makes recommendations for improved handling of LMIC-specific challenges in CEAs of HPV vaccination.

The challenges most commonly identified were estimates of CVG, vaccine coverage and screening coverage. Other distinct challenges acknowledged by only a few studies were interruption of screening programme, no treatment following detection, loss of follow-up and sexual mixing parameters. CVG was reported to significantly affect policy recommendation by the majority of studies. Vaccine coverage and screening coverage parameters were reported to significantly affect the policy recommendation by a few of the studies.

Previous literature has identified the scarcity, quality and accessibility of data as a key challenge for those conducting and using economic evaluations in many LMICs in general [53]. Our analysis confirms this observation in the particular case of HPV vaccination. CVG, screening coverage and vaccine coverage parameters are inevitably uncertain as there typically was no prior experience of HPV vaccination, and cervical cancer screening was mainly opportunistic in many of the contexts in which the studies were conducted. Furthermore, there was considerable uncertainty in the CVG because of a lack of clarity on the vaccine's cost prior to the pricing agreement achieved by Gavi in 2013. In the specific case of the CVG, the majority of the studies attempted to respond to such data constraints by deriving a CVG estimate through a composite costing approach. Nonetheless, they failed to report and justify the basis for the composite cost items. Vaccine coverage and screening coverage parameters were simply assumed rather than being based on empirical evidence of other vaccination programmes in the same setting or HPV vaccination programmes in related settings. The typical base case assumption of $70 \%$ appears optimistic given what has been achieved in other programmes $[22,25,30]$.

\subsection{Cost per Vaccinated Girl}

As has been stated previously, the lack of existing infrastructure to support vaccination of adolescent girls means that delivery and programme costs could contribute substantially to total vaccination costs in LMICs [15]. Unlike new infant vaccines, which may be added to an existing infant vaccine delivery system, HPV vaccination requires the development of a new vaccine delivery service in order to achieve the required doses since the target age is different. Surprisingly, this need for an HPV-specific delivery service was not accounted for by some of the studies. Those that did consider the extra cost associated with HPV 
Table 1 Range used in sensitivity analysis and the rationale for use

\begin{tabular}{|c|c|c|c|c|}
\hline No. & First author, year & $\begin{array}{l}\text { Distinct } \\
\text { uncertain } \\
\text { parameters }\end{array}$ & Range used in sensitivity analysis & Rationale \\
\hline 1 & $\begin{array}{l}\text { Aponte-Gonzalez } \\
\text { et al. } 2013[20]\end{array}$ & CVG & $\begin{array}{l}\text { Bivalent vaccine: US\$133-487 } \\
\text { Quadrivalent vaccine: US\$157-282 }\end{array}$ & $\begin{array}{l}\text { Range of vaccine cost was to determine threshold price } \\
\text { at which vaccine will be cost-effective }\end{array}$ \\
\hline 2 & $\begin{array}{l}\text { Berkhof et al. } 2013 \\
\text { [21] }\end{array}$ & None & - & - \\
\hline 3 & $\begin{array}{l}\text { Campos et al. } 2012 \\
\text { [22] }\end{array}$ & $\begin{array}{l}\text { CVG, vaccine } \\
\text { coverage }\end{array}$ & $\begin{array}{l}\text { CVG: I } \$ 5-200 \\
\text { Vaccine coverage: base coverage of } \\
70 \% \text { and attrition rate per dose of } \\
15 \% \text { varied from } 0 \text { to } 40 \%\end{array}$ & $\begin{array}{l}\text { Range of CVG was to determine threshold price at } \\
\text { which vaccine will be cost-effective since CVG was } \\
\text { unknown. Vaccine coverage was assumed }\end{array}$ \\
\hline 4 & $\begin{array}{l}\text { Canfell et al. } 2011 \\
\text { [23] }\end{array}$ & None & - & - \\
\hline 5 & $\begin{array}{l}\text { Colantonio et al. } \\
2009[24]\end{array}$ & None & - & - \\
\hline 6 & $\begin{array}{l}\text { Diaz et al. } 2008 \\
\text { [25] }\end{array}$ & CVG & CVG: I\$5-360 & $\begin{array}{l}\text { Range of CVG was to determine threshold price at } \\
\text { which vaccine will be cost-effective since CVG was } \\
\text { unknown }\end{array}$ \\
\hline 7 & $\begin{array}{l}\text { Fonseca et al. } 2013 \\
\text { [26] }\end{array}$ & $\begin{array}{l}\text { CVG, vaccine } \\
\text { coverage }\end{array}$ & $\begin{array}{l}\text { CVG: US\$15-500 } \\
\text { Vaccine coverage: } 30-100 \%\end{array}$ & $\begin{array}{l}\text { Range of CVG and vaccine coverage were authors' } \\
\text { judgment regarding uncertainty associated with } \\
\text { parameters }\end{array}$ \\
\hline 8 & $\begin{array}{l}\text { Ginsberg et al. } \\
2009 \text { [27] }\end{array}$ & CVG & $\begin{array}{l}\text { CVG: US\$1.8-6 (i.e. US\$0.6-2 per } \\
\text { dose) }\end{array}$ & Range of CVG was assumed \\
\hline 9 & $\begin{array}{l}\text { Goldie et al. } 2007 \\
\text { [30] }\end{array}$ & $\begin{array}{l}\text { CVG, vaccine } \\
\text { coverage }\end{array}$ & $\begin{array}{l}\text { CVG: I } \$ 25-450 \\
\text { Vaccine coverage: } 10-100 \%\end{array}$ & $\begin{array}{l}\text { Range of CVG was to determine threshold price at } \\
\text { which vaccine will be cost-effective since CVG was } \\
\text { unknown. Range of vaccine coverage was assumed }\end{array}$ \\
\hline 10 & $\begin{array}{l}\text { Goldie et al. } 2008 \\
\text { [28] }\end{array}$ & $\begin{array}{l}\text { CVG, vaccine } \\
\text { coverage }\end{array}$ & $\begin{array}{l}\text { CVG: I } \$ 5-430 \\
\text { Vaccine coverage: } 0-90 \%\end{array}$ & $\begin{array}{l}\text { Range of CVG was to determine threshold price at } \\
\text { which vaccine will be cost-effective since CVG was } \\
\text { unknown. Range of vaccine coverage was assumed }\end{array}$ \\
\hline 11 & $\begin{array}{l}\text { Goldie et al. } 2008 \\
\text { [29] }\end{array}$ & CVG & CVG: I\$5-360 & $\begin{array}{l}\text { Range of CVG was to determine threshold price at } \\
\text { which vaccine will be cost-effective since CVG was } \\
\text { unknown }\end{array}$ \\
\hline 12 & $\begin{array}{l}\text { Goldie et al. } 2008 \\
\text { [32] }\end{array}$ & CVG & CVG: I\$5-50 & $\begin{array}{l}\text { Range of CVG was to determine threshold price at } \\
\text { which vaccine will be cost-effective since CVG was } \\
\text { unknown }\end{array}$ \\
\hline 13 & $\begin{array}{l}\text { Goldie et al. } 2012 \\
\text { [31] }\end{array}$ & None & - & - \\
\hline 14 & $\begin{array}{l}\text { Gutierrez-Aguado, } \\
2011[33]\end{array}$ & None & - & - \\
\hline 15 & $\begin{array}{l}\text { Gutierrez-Delgado } \\
\text { et al. } 2008 \text { [34] }\end{array}$ & CVG & CVG: US\$15.9-80 per dose & $\begin{array}{l}\text { Range of vaccine cost was to determine threshold price } \\
\text { at which vaccine will be cost-effective }\end{array}$ \\
\hline 16 & $\begin{array}{l}\text { Insinga et al. } 2007 \\
\text { [35] }\end{array}$ & $\begin{array}{l}\text { Vaccine } \\
\text { coverage }\end{array}$ & Vaccine coverage: $20-85 \%$ & Range of vaccine coverage was assumed \\
\hline 17 & Jit et al. 2014 [36] & Not applicable & - & - \\
\hline 18 & $\begin{array}{l}\text { Kawai et al. } 2012 \\
\text { [37] }\end{array}$ & None & - & - \\
\hline 19 & $\begin{array}{l}\text { Khatibi et al. } 2014 \\
\text { [38] }\end{array}$ & None & - & - \\
\hline 20 & $\begin{array}{l}\text { Kiatpongsan and } \\
\text { Kim, } 2014 \text { [39] }\end{array}$ & Not applicable & - & - \\
\hline 21 & $\begin{array}{l}\text { Kim et al. } 2007 \\
\text { [40] }\end{array}$ & CVG & CVG: I\$25-400 & $\begin{array}{l}\text { Range of CVG was to determine threshold price at } \\
\text { which vaccine will be cost-effective since CVG was } \\
\text { unknown }\end{array}$ \\
\hline
\end{tabular}


Table 1 continued

\begin{tabular}{|c|c|c|c|c|}
\hline No. & First author, year & $\begin{array}{l}\text { Distinct } \\
\text { uncertain } \\
\text { parameters }\end{array}$ & Range used in sensitivity analysis & Rationale \\
\hline 22 & $\begin{array}{l}\text { Kim et al. } 2008 \\
\text { [42] }\end{array}$ & $\begin{array}{l}\text { CVG, vaccine } \\
\text { and } \\
\text { screening } \\
\text { coverage }\end{array}$ & $\begin{array}{l}\text { CVG: } \text { I } \$ 10-450 \\
\text { Vaccine coverage: } 20-100 \% \\
\text { Screening coverage: } 20-100 \%\end{array}$ & $\begin{array}{l}\text { Range of CVG was to determine threshold price at } \\
\text { which vaccine will be cost-effective since CVG was } \\
\text { unknown. Ranges of vaccine and screening coverage } \\
\text { rate were assumed }\end{array}$ \\
\hline 23 & $\begin{array}{l}\text { Kim et al. } 2011 \\
\text { [44] }\end{array}$ & Not applicable & - & - \\
\hline 24 & $\begin{array}{l}\text { Kim et al. } 2013 \\
\text { [41] }\end{array}$ & CVG & CVG: I\$5-360 & $\begin{array}{l}\text { Range of CVG was to determine threshold price at } \\
\text { which vaccine will be cost-effective since CVG was } \\
\text { unknown }\end{array}$ \\
\hline 25 & $\begin{array}{l}\text { Kim et al. } 2013 \\
{[43]}\end{array}$ & CVG & CVG: I\$5-500 & $\begin{array}{l}\text { Range of CVG was to determine threshold price at } \\
\text { which vaccine will be cost-effective since CVG was } \\
\text { unknown }\end{array}$ \\
\hline 26 & $\begin{array}{l}\text { Levin et al. } 2015 \\
\text { [45] }\end{array}$ & None & - & - \\
\hline 27 & $\begin{array}{l}\text { Praditsitthikorn } \\
\text { et al. } 2011[46]\end{array}$ & $\begin{array}{l}\text { CVG, } \\
\text { screening } \\
\text { coverage }\end{array}$ & $\begin{array}{l}\text { CVG: Bt3530-15,000 (I\$290-1233) } \\
\text { Screening coverage: } 20-80 \%\end{array}$ & $\begin{array}{l}\text { Range of CVG was to determine threshold price at } \\
\text { which vaccine will be cost-effective. Range of } \\
\text { screening coverage was assumed }\end{array}$ \\
\hline 28 & $\begin{array}{l}\text { Reynales- } \\
\text { Shigematsu et al. } \\
2009 \text { [47] }\end{array}$ & $\begin{array}{l}\text { CVG, Vaccine } \\
\text { coverage }\end{array}$ & $\begin{array}{l}\text { CVG: US\$45-250 } \\
\text { Vaccine coverage: } 0-100 \%\end{array}$ & $\begin{array}{l}\text { Range of CVG was to determine threshold price at } \\
\text { which vaccine will be cost-effective since CVG was } \\
\text { unknown. Range of vaccine coverage rate was } \\
\text { assumed }\end{array}$ \\
\hline 29 & $\begin{array}{l}\text { Sharma et al. } 2012 \\
\text { [48] }\end{array}$ & CVG & CVG: I\$10-500 & $\begin{array}{l}\text { Range of CVG was to determine threshold price at } \\
\text { which vaccine will be cost-effective since CVG was } \\
\text { unknown }\end{array}$ \\
\hline 30 & $\begin{array}{l}\text { Sinanovic et al. } \\
2009[49]\end{array}$ & CVG & CVG: US\$192-480 per dose & $\begin{array}{l}\text { Range of CVG was to determine threshold price at } \\
\text { which vaccine will be cost-effective }\end{array}$ \\
\hline 31 & $\begin{array}{l}\text { Termrungruanglert } \\
\text { et al. } 2012[50]\end{array}$ & CVG & CVG: Bt6189-12,378 (US\$177-354) & $\begin{array}{l}\text { Authors did not specify how CVG was estimated, nor } \\
\text { the reason for the range used in sensitivity analysis }\end{array}$ \\
\hline 32 & $\begin{array}{l}\text { Tracy et al. } 2014 \\
\text { [51] }\end{array}$ & None & - & - \\
\hline 33 & $\begin{array}{l}\text { Vanni et al. } 2012 \\
\text { [52] }\end{array}$ & CVG & $\begin{array}{l}\text { CVG: US\$25-556 (US\$5-120 per } \\
\text { dose) }\end{array}$ & $\begin{array}{l}\text { Range of CVG was to determine threshold price at } \\
\text { which vaccine will be cost-effective since CVG was } \\
\text { unknown }\end{array}$ \\
\hline
\end{tabular}

$B t$ Baht, $C C$ cervical cancer, $C V G$ cost per vaccinated girl, $H P V$ human papillomavirus, $I \$$ international dollars, US\$ US dollars

vaccine delivery did not specify the basis for the cost estimate and did not account for regional cost differences. Regional cost differences matter for rural areas, which are expected to have higher delivery costs than urban centres as they may lack good road access and electricity supply to maintain cold chain equipment.

Our proposal for refining CVG estimates for CEA of HPV vaccination (i.e. cost of vaccine itself and all of the costs of administration, distribution and implementation) involves adaptation, to the country of study, of HPV vaccine delivery costs from other countries where vaccination has been implemented. A number of pilot projects on HPV vaccine delivery in LMICs have been conducted [54, 55]. These studies used various delivery methods, including school-based periodic intensification of routine immunization (PIRI), outreach vaccine delivery, PIRI integrated with other preventive health activities, or routine provision of health facility (fixed site)-based activities [8]. The cost components of HPV vaccination from the pilot projects typically include social mobilization, training, vaccine procurement, vaccination, cold storage, waste management and administration/supervision [54].

The adaptation process will firstly be to identify a pilot HPV vaccine delivery project conducted in a similar environment as the country of study. Then substitute as many cost items of the HPV vaccine delivery project as possible with country-specific costs. It may also be necessary to combine different delivery methods in order to target non-schooling populations. Fortunately, there is now greater clarity on the vaccine cost for many countries, since Gavi has secured a vaccine price of US\$4.50 for eligible nations (countries with less than US\$1580 per capita 
Table 2 Effect of sensitivity analysis on policy recommendation $(n=33)$

\begin{tabular}{|c|c|c|c|c|c|}
\hline \multirow[t]{2}{*}{ No. } & \multirow[t]{2}{*}{ First author, year } & \multicolumn{4}{|c|}{ Policy recommendation } \\
\hline & & $\begin{array}{l}\text { Base case } \\
\text { analysis }^{\mathrm{a}}\end{array}$ & CVG & $\begin{array}{l}\text { Screening } \\
\text { coverage }\end{array}$ & $\begin{array}{l}\text { Vaccination } \\
\text { coverage }\end{array}$ \\
\hline 1 & Aponte-Gonzalez et al. 2013 [20] & - & + & NA & NA \\
\hline 2 & Berkhof et al. 2013 [21] & $+{ }^{\mathrm{b}}$ & NA & + & NA \\
\hline 3 & Campos et al. 2012 [22] & + & - & + & + \\
\hline 4 & Canfell et al. 2011 [23] & NA & NA & NA & NA \\
\hline 5 & Colantonio et al. 2009 [24] & + & NA & + & NA \\
\hline 6 & Diaz et al. 2008 [25] & + & - & NA & NA \\
\hline 7 & Fonseca et al. 2013 [26] & + & NA & NA & - \\
\hline 8 & Ginsberg et al. 2009 [27] & + & - & NA & NA \\
\hline 9 & Goldie et al. 2007 [30] & + & - & NR & NR \\
\hline 10 & Goldie et al. 2008 [28] & + & - & NA & NR \\
\hline 11 & Goldie et al. 2008 [29] & + & - & NR & NR \\
\hline 12 & Goldie et al. 2008 [32] & $+{ }^{\mathrm{b}}$ & - & NR & NR \\
\hline 13 & Goldie et al. 2012 [31] & + & + & NA & NA \\
\hline 14 & Gutierrez-Aguado, 2011 [33] & + & + & NA & NA \\
\hline 15 & Gutierrez-Delgado et al. 2008 [34] & - & + & NA & NA \\
\hline 16 & Insinga et al. 2007 [35] & + & NA & NA & - \\
\hline 17 & Jit et al. 2014 [36] & NA & NA & NA & NA \\
\hline 18 & Kawai et al. 2012 [37] & + & NR & NA & NA \\
\hline 19 & Khatibi et al. 2014 [38] & - & - & NA & NA \\
\hline 20 & Kiatpongsan and Kim, 2014 [39] & NA & NA & NA & NA \\
\hline 21 & Kim et al. 2007 [40] & + & - & NA & + \\
\hline 22 & Kim et al. 2008 [42] & + & - & - & - \\
\hline 23 & Kim et al. 2011 [44] & NA & NA & NA & NA \\
\hline 24 & Kim et al. 2013 [41] & $+^{\mathrm{b}}$ & - & NR & NR \\
\hline 25 & Kim et al. 2013 [43] & $+^{\mathrm{b}}$ & - & NR & NR \\
\hline 26 & Levin et al. 2015 [45] & + & + & NR & + \\
\hline 27 & Praditsitthikorn et al. 2011 [46] & - & $+^{\mathrm{c}}$ & + & - \\
\hline 28 & Reynales-Shigematsu et al. 2009 [47] & + & - & NR & - \\
\hline 29 & Sharma et al. 2012 [48] & + & - & + & + \\
\hline 30 & Sinanovic et al. 2009 [49] & $+^{c}$ & $+{ }^{\mathrm{d}}$ & NA & NA \\
\hline 31 & Termrungruanglert et al. 2012 [50] & + & - & NA & + \\
\hline 32 & Tracy et al. 2014 [51] & + & NA & NA & + \\
\hline \multirow[t]{3}{*}{33} & Vanni et al. 2012 [52] & + & - & + & + \\
\hline & Number of studies that parameter uncertainty affected policy recommendation & & 18 & 2 & 4 \\
\hline & Number of studies that did not report the effect of parameter uncertainty & & 1 & 7 & 6 \\
\hline
\end{tabular}

+ Accept vaccination, - reject vaccination, $C V G$ cost per vaccinated girl, $N A$ not applicable, $N R$ not reported

${ }^{a}$ Some studies were denoted NA since the primary focus was to explore price range for which vaccine would be cost-effective or to develop a generic model for cost-effectiveness analysis

${ }^{b}$ Majority of the countries in multi-country study

c Accept vaccination in combination with screening

${ }^{d}$ Vaccine is more cost-effective than screening

income over the past 3 years) [56]. Repeating the analyses using this price would now considerably reduce uncertainty in the outcomes for the Gavi-eligible sub-Saharan African countries reviewed here [22, 25, 32, 36, 38, 41, 44]. Non-
Gavi-eligible countries should use the lowest public sector price of US $\$ 13$ offered by HPV vaccine manufacturers [56], as non-Gavi-eligible LMICs could likely negotiate price down to this level, as achieved by the Pan American 
Health Organization countries [56]. It is important to note that some of the more recent studies reviewed have already adopted the approach we recommend for assessing the CVG $[36,45]$.

\subsection{Vaccine Coverage}

The incremental cost-effectiveness ratio (ICER) of many interventions in general may be invariant with the proportion of the population treated, as costs and health effects increase proportionately as coverage increases. It is uncertain quite to what extent this can be expected to hold in the case of HPV vaccination, due to herd immunity effects, which mean the effectiveness of vaccination does not necessarily rise in proportion with coverage. For instance, one of the studies showed that at coverage levels between 50 and $70 \%$, indirect effect of vaccination accounted for an additional $10 \%$ cancer reduction compared with the mean projected estimate in the base case [30]. Moreover, the ICER may not be invariant with coverage if a vaccination programme's fixed costs of organization and distribution are not small relative to the variable costs of vaccine doses and administration. However, what matters more is not that the ICER might vary with vaccine coverage, but that it might vary to such an extent that the policy recommendation might change. Indeed, our results suggest the coverage rate appears to be a relevant parameter, as it altered the policy recommendation in just under half of the studies reviewed (four out of nine) when varied in sensitivity analyses.

The vaccination rate of $70 \%$ commonly assumed by the reviewed studies does not appear justified by the rates achieved in practice by many LMICs. Even though schoolbased HPV vaccination demonstration projects in some LMIC settings have achieved high vaccine coverage of between 80 and $95 \%$ [57], the concern is that school-based vaccination may miss a large number of girls not attending schools. Similarly, some girls could also be systematically excluded because they live in remote locations. Furthermore, as of 2010, most of the Middle East and North African countries that adopted adolescent vaccine programmes to provide catch-up or booster vaccine administered as recommended by the Eastern Mediterranean Region of WHO (EMR) had low vaccine coverage, ranging from 17 to $58 \%$ [6]. Even many high-income country HPV vaccination programmes have failed to achieve coverage rates as high as $70 \%$. For example, low rates of complete HPV vaccination coverage have been observed both in the target and catch-up groups in France (33.3 and $23.7 \%$, respectively) [58]. Only a few developed countries, such as Australia, Canada, Portugal and the UK, have achieved HPV vaccination coverage rates above $70 \%$ [15]. This has been attributed to the advantages of being able to rely on existing adolescent health systems such as school nurses [59].

Instead of assuming an unrepresentatively high coverage rate, we believe that it will be most appropriate to use previous country-specific vaccine coverage performance as a base case assumption. Coverage rates of adolescent catch-up or booster vaccination programmes could be used in countries or regions where such programmes are in place, such as in the Middle East and North African region [6]. However, in the absence of an adolescent vaccination programme, coverage of diphtheria-tetanus-pertussis (DTP3) could serve as a good proxy, especially as vaccination coverage with the third dose of DTP vaccines among infants is the main indicator of immunization programmes' performance and is used as a benchmark to qualify for Gavi support [6].

\subsection{Screening Coverage}

Effective screening programmes require a number of properties, including a well-organized call-recall system, an accurate register of women and their screening history, adequate follow-up and treatment for screen-positive women, rigorous quality control to ensure good test accuracy and good screening coverage rates across the eligible population. Accordingly, there are many screening variables for CEA modellers to consider when specifying their analyses. In particular, modellers face a choice of whether they should simulate screening as is as effective as possible given available resources, or if they should simulate screening as is currently practised.

We have primarily considered the choice of modelling ideal or actual screening in terms of screening coverage. This is because the assumed coverage rate is a key indicator of whether the analysts are attempting to model the best possible screening performance or what is more likely to be attained in practice. Our results show that a clear majority of the studies (seven of the nine reviewed) chose to simulate organized national screening programmes with relatively high coverage rates, while the remaining two modelled screening coverage as currently achieved by the health system.

There is no clear answer which approach is most appropriate. Conventional CEA methods suggest that all possible alternatives should be considered; therefore, wellfunctioning national screening programmes with good coverage appear relevant comparators to include. Whereas, a more pragmatic view would be that many LMICs will struggle to implement comprehensive national screening programmes with high coverage rates. The relevant concern regarding the assessment of vaccination is that assuming unrepresentatively high screening rates will result in under-estimates of the beneficial effects of 
vaccination, as primary prevention will lead to greater added benefit when there is little secondary prevention. Such assumptions therefore lead to unnecessarily unfavourable cost-effectiveness estimates for vaccination.

These concerns are particularly relevant for those LMICs that have no prior experience of implementing national screening services. Accordingly, it is difficult to make informed assumptions about what the potential for organized screening is if there is no current programme. Indeed, it may be questioned if such countries will be able to implement a well-organized, high-quality screening programme, in the medium term at least.

The experience of South Africa provides a useful illustration of this issue. It is the only country within the African region with an organized national cervical cancer screening programme and has achieved cervical cancer screening coverage of less than $20 \%$ [12]. Some Latin American countries such as Costa Rica, Bolivia, El Salvador, Nicaragua, and Panama have screening coverage rates ranging from 10 to $20 \%$ [14]. With limited availability of cervical cancer screening tests and procedures at the primary health care level (cervical cytology available in $57 \%$ and acetic acid visualization in $29 \%$ of the primary health care centres in LMICs), it is doubtful whether coverage levels of $70 \%$ are achievable in LMICs [60]. Accordingly, we recommend the use of cervical cancer screening coverage rates of countries in the same geographical region for analysis, assuming an organized national screening or increased future predicted screening. For instance, in the absence of local data, African countries could employ the South African screening rates as the base case rather than assuming $70 \%$ coverage.

Although there is considerable uncertainty regarding what coverage rates are feasible, it is notable that the policy recommendations appear less sensitive to assumptions regarding screening coverage than those regarding vaccination coverage, as only two of the nine reviewed studies saw their policy recommendations reverse when screening adherence rates were varied in sensitivity analyses.

\subsection{Sensitivity Analyses}

A general response to the data limitations taken by many of the reviewed studies was to examine the consequences of parameter uncertainty in a sensitivity analysis. Although this is an appropriate response to uncertainty, some further issues arise from exactly how such analyses are conducted. One particular difficulty occurred when broad ranges of input parameters were specified for parameters such as the CVG, vaccine coverage and screening coverage, which resulted in a broad range of cost-effectiveness outcomes, leaving it unclear as to whether the intervention was costeffective or not.
It is undeniable that considerable uncertainty does exist in key parameters. Accordingly, large input parameter ranges are necessary to a degree. However, the concern is not necessarily just the size of the input parameter ranges, but whether the analyses provided a justification for the ranges used. The rationale for the input parameter ranges used in the sensitivity analyses was typically not given in the studies reviewed here. Accordingly, it is unclear if the resulting uncertainty in cost-effectiveness estimates is simply a fair reflection of the inherent decision uncertainty resulting from appropriately quantified input parameter ranges or if arbitrarily large input parameter ranges are leading to unnecessary uncertainty for decision makers. While there are theoretical arguments to suggest that such decision uncertainty should not influence policy [61], evidence suggests that uncertainty does matter to decision makers [62]. Accordingly, the concern that analysts may be overestimating the amount of uncertainty and placing an unnecessary burden on LMIC decision makers is relevant.

Our recommendation for the conduct of uncertainty analysis is that the input parameter ranges chosen should be chosen so they meaningfully reflect plausible ranges rather than being arbitrarily chosen. While parameter uncertainty is inevitable, if it is at all possible, more precise input parameter distributions that yield less uncertain CEA outcomes should be used. Similarly, we suggest that the rationale for the input parameter ranges should be described carefully. Table 3 contains specific recommendations for the reduction of the decision uncertainty of important input parameters in this case. These steps should ensure greater clarity for decision makers for LMICs in their policy choices.

\subsection{Context of Implementation}

The issue of screening and vaccine coverage examined in this review can also be considered in the context of the literature examining the implementation of interventions. Previous work has drawn attention to the issue that guidelines, such as national screening and vaccination guidelines, are not always implemented as planned [63]. Failure to adequately implement cost-effective interventions imposes costs in terms of lost net health benefit [64]. Similarly, achieving implementation in accordance with guidelines will typically require additional resources, the costs of which may be overlooked in applied CEAs.

The example of cervical cancer prevention considered in this review is particularly relevant to the implementation literature for two reasons. The first is that the challenges of implementation are particularly relevant where the costeffectiveness of one intervention is contingent on the level 
Table 3 Recommendation for improving the precision of policy recommendations of cost-effectiveness estimates of HPV vaccination in LMICs

\begin{tabular}{|c|c|c|}
\hline Parameter & Recommendation & Example \\
\hline \multicolumn{3}{|l|}{ Cost per vaccinated girl (CVG) } \\
\hline Vaccine price & $\begin{array}{l}\text { Use the HPV vaccine price offered by the } \\
\text { Vaccine Alliance (Gavi) for countries eligible } \\
\text { for Gavi support and lowest public sector } \\
\text { price offered by HPV vaccine manufacturers } \\
\text { for non-Gavi-eligible countries }\end{array}$ & $\begin{array}{l}\text { US } \$ 4.50 \text { per dose for Gavi-eligible } \\
\text { countries and US } \$ 13 \text { per dose for non- } \\
\text { Gavi-eligible countries }\end{array}$ \\
\hline $\begin{array}{l}\text { Other cost (social mobilization, training, } \\
\text { vaccine procurement, vaccination, cold } \\
\text { storage, waste management and } \\
\text { administration/supervision) }\end{array}$ & $\begin{array}{l}\text { Adapt the HPV vaccine delivery cost of other } \\
\text { countries, where it has been established, to } \\
\text { the country of study }\end{array}$ & $\begin{array}{l}\text { Costing of HPV vaccine delivery to school } \\
\text { girls in Mwanza Region, Tanzania } \\
\text { adapted to other sub-Saharan African } \\
\text { countries [54] }\end{array}$ \\
\hline Vaccination coverage rate & $\begin{array}{l}\text { Use previous country-specific vaccine coverage } \\
\text { performance }\end{array}$ & $\begin{array}{l}33 \% \text { coverage of second dose of diphtheria } \\
\text { toxoid, tetanus toxoid and pertussis (DTP) } \\
\text { vaccine in Nigeria [65] }\end{array}$ \\
\hline Screening coverage rate & $\begin{array}{l}\text { Use cervical cancer screening coverage rate of } \\
\text { countries in the same geographical region }\end{array}$ & $\begin{array}{l}<20 \% \text { coverage rate of South Africa for } \\
\text { sub-Saharan African countries [12] }\end{array}$ \\
\hline
\end{tabular}

HPV human papillomavirus, LMICs low- and middle-income countries, US\$ US dollars

of implementation of another, as is the case here with vaccination and screening. Similarly, questions of effective implementation can be expected to be more pressing in an LMIC context, where much of the supporting health systems infrastructure required to achieve consistent service provision to the whole population and good levels of compliance is likely to be weaker than elsewhere.

Our review highlights the choice between modelling cervical cancer prevention strategies according to the national policy guidelines or on the basis of the levels of screening and vaccine coverage that are likely to be achieved in practice. If modellers choose to simulate on the basis of the recommended coverage, then it is necessary to both describe the efforts required to achieve full implementation and to incorporate the additional costs of enhancing implementation.

\section{Conclusion}

This review showed that the majority of the decision analytic models of HPV vaccination did explicitly note that there were LMIC-specific challenges. The challenges were mainly estimates of CVG, vaccine coverage and screening coverage. CVG was reported to significantly affect the policy recommendation in the majority of the studies. Vaccine coverage and screening coverage parameters were also reported to significantly affect the policy recommendation in a few of the studies. CEAs of HPV vaccination could achieve reduced decision uncertainty by adapting cost analysis of HPV vaccine delivery conducted for other countries, observing the outcomes of cervical cancer screening programmes in the same geographical region, and taking into account the country's previous experience with other vaccination programmes.

Acknowledgments The authors are grateful to Lara Christianson for her assistance during the search and retrieval of manuscripts.

\section{Compliance with Ethical Standards}

Conflict of interest OE, JFOM, AGG, CM, TP and SKL declare no competing interests. This study was funded by the Alexander von Humboldt Foundation.

Authors' contribution OE and SKL were responsible for the development of the study design, formulation of study questions and study selection criteria, synthesis of data, and performance of quality assessments. AGG and JFOM contributed in the development of the study design and study selection criteria. $\mathrm{CM}$ was responsible for formulating the search strategy. OE and TP screened the titles and abstracts. OE conducted the quality assessments and was responsible for data extraction. OE drafted the first manuscript, and all the authors contributed to manuscript revisions before the final version. All authors read and approved the final manuscript.

Open Access This article is distributed under the terms of the Creative Commons Attribution-NonCommercial 4.0 International License (http://creativecommons.org/licenses/by-nc/4.0/), which permits any noncommercial use, distribution, and reproduction in any medium, provided you give appropriate credit to the original author(s) and the source, provide a link to the Creative Commons license, and indicate if changes were made.

\section{Appendix 1}

See Table 4. 
Table 4 Details of electronic bibliographic database search strategies (for MEDLINE and EMBASE)

\begin{tabular}{ll}
\hline Database & Search strategy \\
\hline MEDLINE (via & ("Human papillomavirus 6" [mesh] OR "Human papillomavirus 16" [mesh] OR "Human papillomavirus 18” [mesh] \\
PubMed) & OR "Human papillomavirus 31” [mesh] OR Alphapapillomavirus [mesh] OR Papillomavirus* [tiab] OR human \\
& papilloma* [tiab] OR HPV [tiab] OR "Papillomavirus Infections" [mesh] OR Papillomaviridae [mesh] OR \\
& Papillomavirid* [tiab] OR Uterine Cervical Neoplasms [mesh] OR cervix cancer* [tiab] OR cervix carcinom* [tiab] \\
& OR cervix malignan* [tiab] OR cervix neoplas* [tiab] OR cervix tumor* [tiab] OR cervical cancer* [tiab] OR cervical \\
& carcinom* [tiab] OR cervical malignan* [tiab] OR cervical neoplas* [tiab] OR cervical tumor* [tiab] OR Cervical \\
& Intraepithelial Neoplasia [mesh] OR Cervical Intraepithelial Neoplasia [tiab] OR CIN [tiab])
\end{tabular}
AND

(Vaccination [mesh] OR mass vaccination [mesh] OR Papillomavirus Vaccines [mesh] OR vaccin* [tiab] OR immunization [mesh] OR Immunization Programs [mesh] OR immuni* [tiab] OR "human papillomavirus vaccine L1, type 6,11,16,18" [Supplementary Concept] OR "human papillomavirus vaccine, L1 type 16, 18" [Supplementary Concept] OR Gardasil [tiab] OR Cervarix [tiab])

AND

(“2006/01/01”[dp]: “3000”[dp])

AND

(Economics [mesh] OR Quality of Life [mesh:NoExp] OR Value of Life [mesh:NoExp] OR Quality-Adjusted Life Years [mesh:NoExp] OR Models, Economic [mesh:NoExp] OR Markov Chains [mesh:NoExp] OR Monte Carlo Method [mesh:NoExp] OR Decision trees [mesh:NoExp] OR economic* [tiab] OR cost* [tiab] OR costing* [tiab] OR costly [tiab] OR costed [tiab] OR price* [tiab] OR pricing* [tiab] OR pharmacoeconomic* [tiab] OR pharmaco-economic* [tiab] OR budget* [tiab] OR expenditure* [tiab] OR (value [tiab] AND (money [tiab] OR monetary [tiab])) OR fee [tiab] OR fees [tiab] OR quality of life [tiab] OR qol* [tiab] OR hrqol* [tiab] OR quality adjusted life year* [tiab] OR qaly* [tiab] OR cba [tiab] OR cea [tiab] OR cua [tiab] OR utilit* [tiab] OR markov* [tiab] OR monte carlo [tiab] OR (decision [tiab] AND (tree* [tiab] OR analys* [tiab] OR model* [tiab])) OR ((clinical [tiab] OR critical [tiab] OR patient [tiab]) AND (path* [tiab] OR pathway* [tiab])) OR (managed [tiab] AND (care [tiab] OR network* [tiab])))

EMBASE

('Human papillomavirus type 6'/exp OR 'Human papillomavirus type 16'/exp OR 'Human papillomavirus type 18'/exp OR 'Human papillomavirus type 31'/exp OR 'Alphapapillomavirus'/exp OR 'Papillomavirus Infection'/exp OR 'Papilloma virus'/exp OR 'uterine cervix cancer'/exp OR (Papillomavirus* OR human papilloma* OR HPV OR Papillomavirid*):ab,ti OR ((cervix OR cervical) NEAR/3 (cancer* OR carcinoma* OR malignanc* OR neoplasm* OR tumor*)):ab,ti OR 'uterine cervix carcinoma in situ'/exp OR ("Cervical Intraepithelial Neoplasia” OR CIN):ab,ti)

AND

('Immunization'/exp OR ‘Cancer immunization'/exp OR 'mass immunization'/exp OR 'Vaccination'/exp OR 'Wart virus vaccine'/exp OR (vaccin* OR immuni* OR Gardasil OR Cervarix):ab,ti OR 'preventive health service'/exp)

AND

$[1-1-2006] / \mathrm{sd}$ NOT $[1-1-3000] / \mathrm{sd}$

AND

('health economics'/exp OR 'health care cost'/exp OR 'quality of life'/exp OR 'quality adjusted life year'/exp OR 'Monte Carlo method'/exp OR 'decision tree'/exp OR (economic* OR cost* OR costing* OR costly OR costed OR price* OR pricing* OR pharmacoeconomic* OR budget* OR expenditure* OR fee OR fees OR 'quality of life' OR qol* OR hrqol* OR qaly* OR CBA OR CEA OR CUA OR utilit* OR markov*):ab,ti OR (pharmaco NEXT/1 economic*):ab,ti OR (value NEAR/1 (money OR monetary)):ab,ti OR ('quality adjusted life' NEXT/1 year*):ab,ti OR (monte NEXT/1 carlo):ab,ti OR (decision NEXT/3 (tree* OR analys* OR model*)):ab,ti OR ((clinical OR critical OR patient) NEXT/1 (path* OR pathway*)):ab,ti OR (managed NEXT/3 (care OR network*)):ab,ti)

\section{Appendix 2}

See Table 5 . 


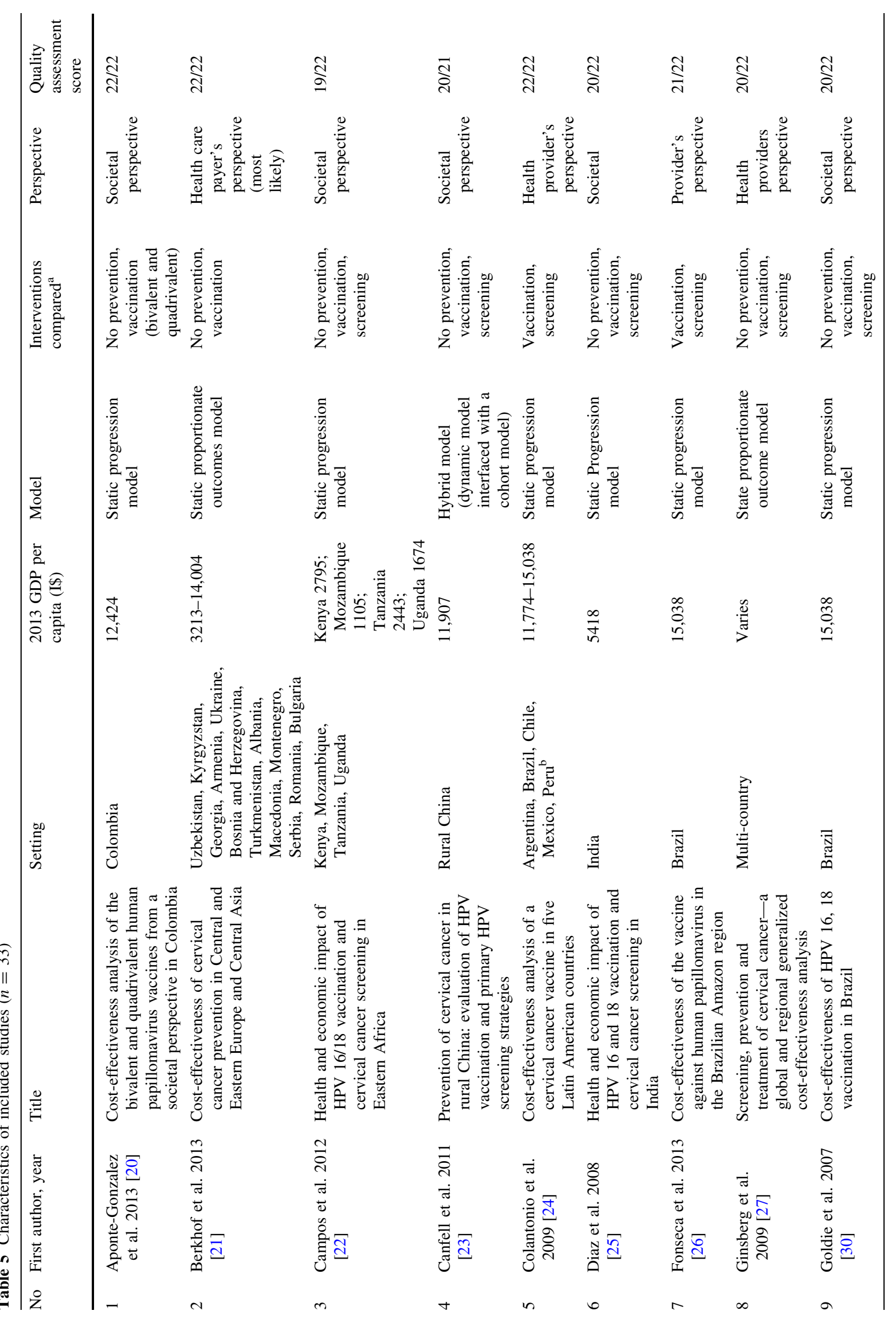




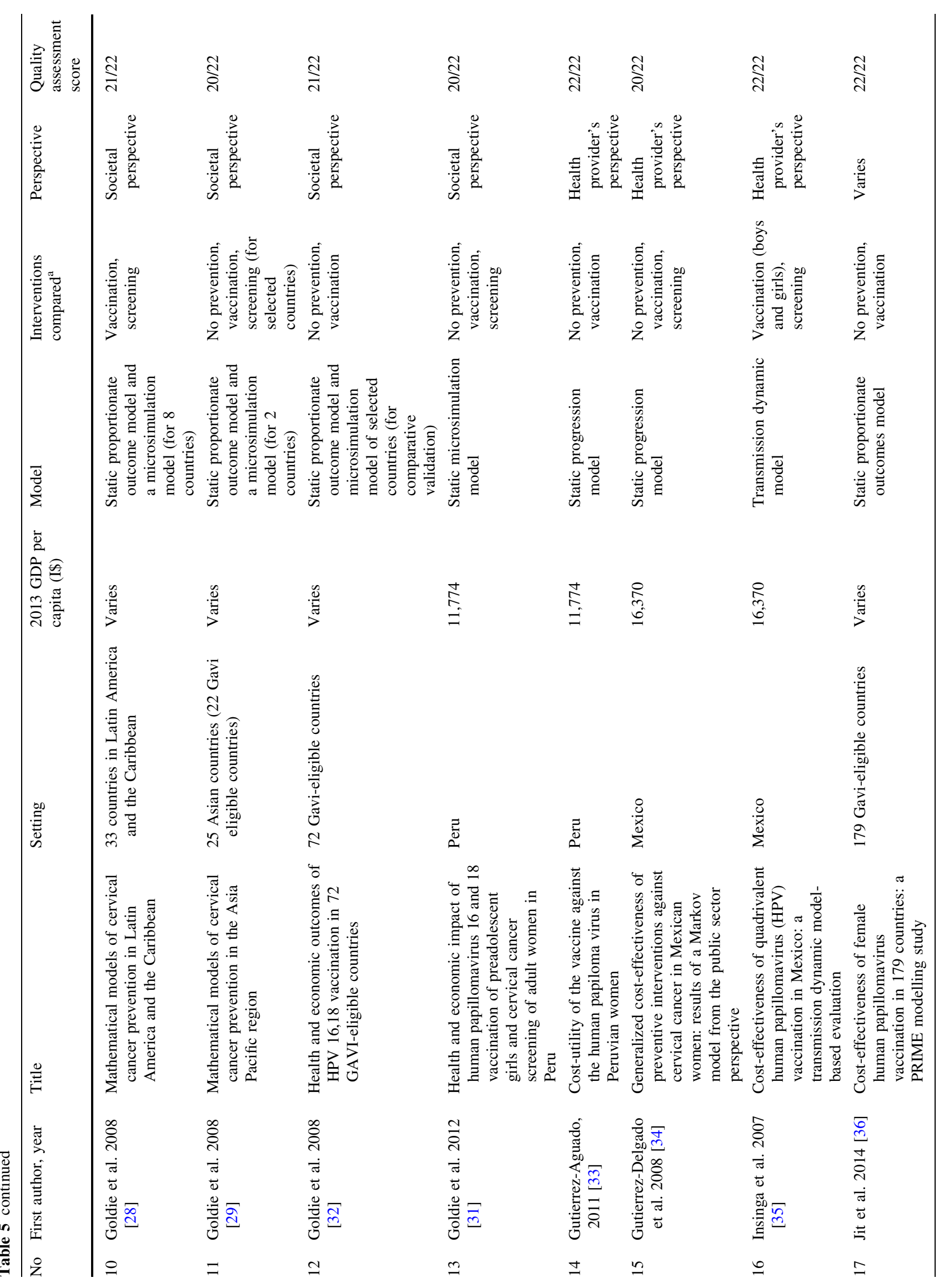




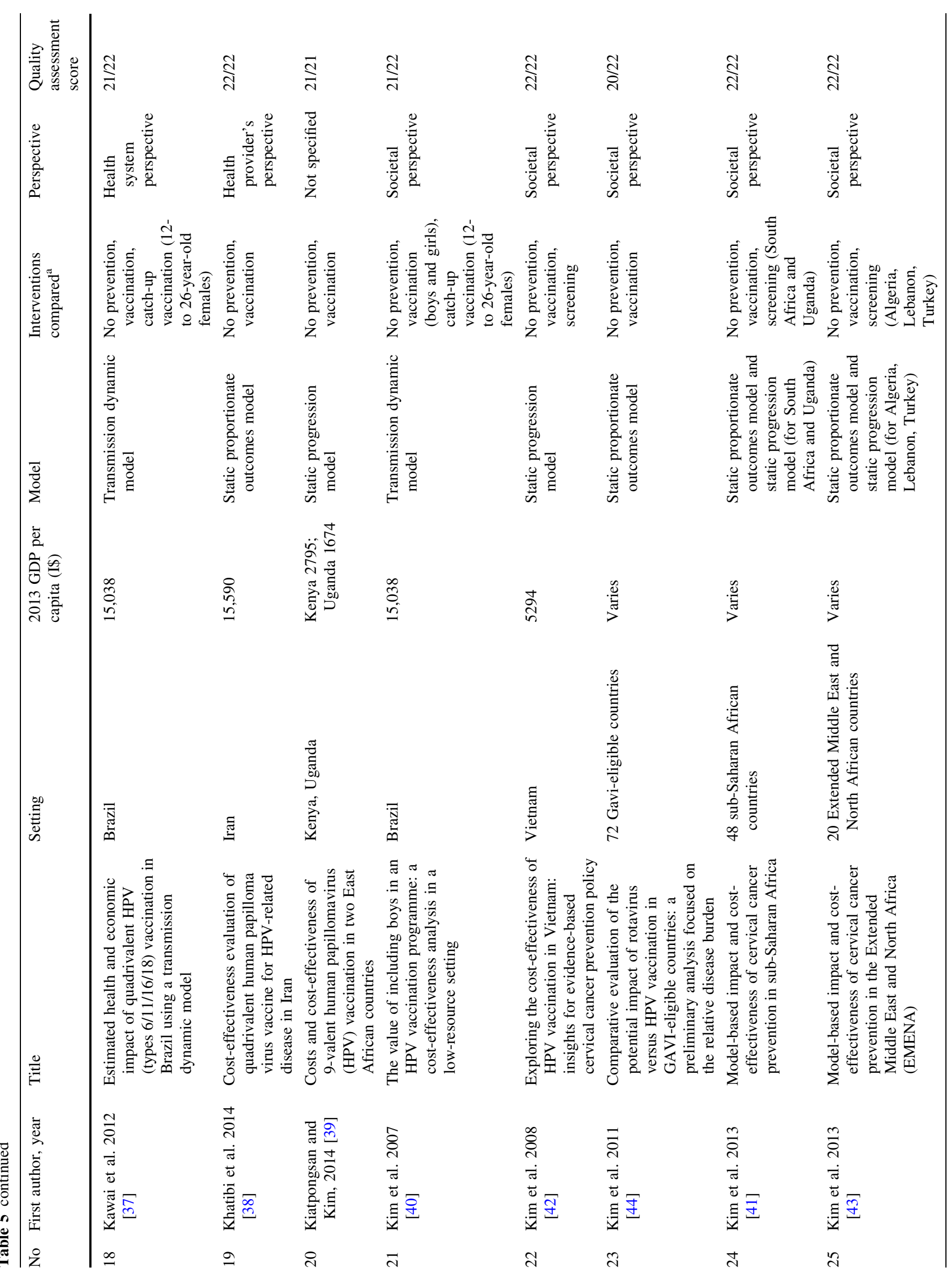




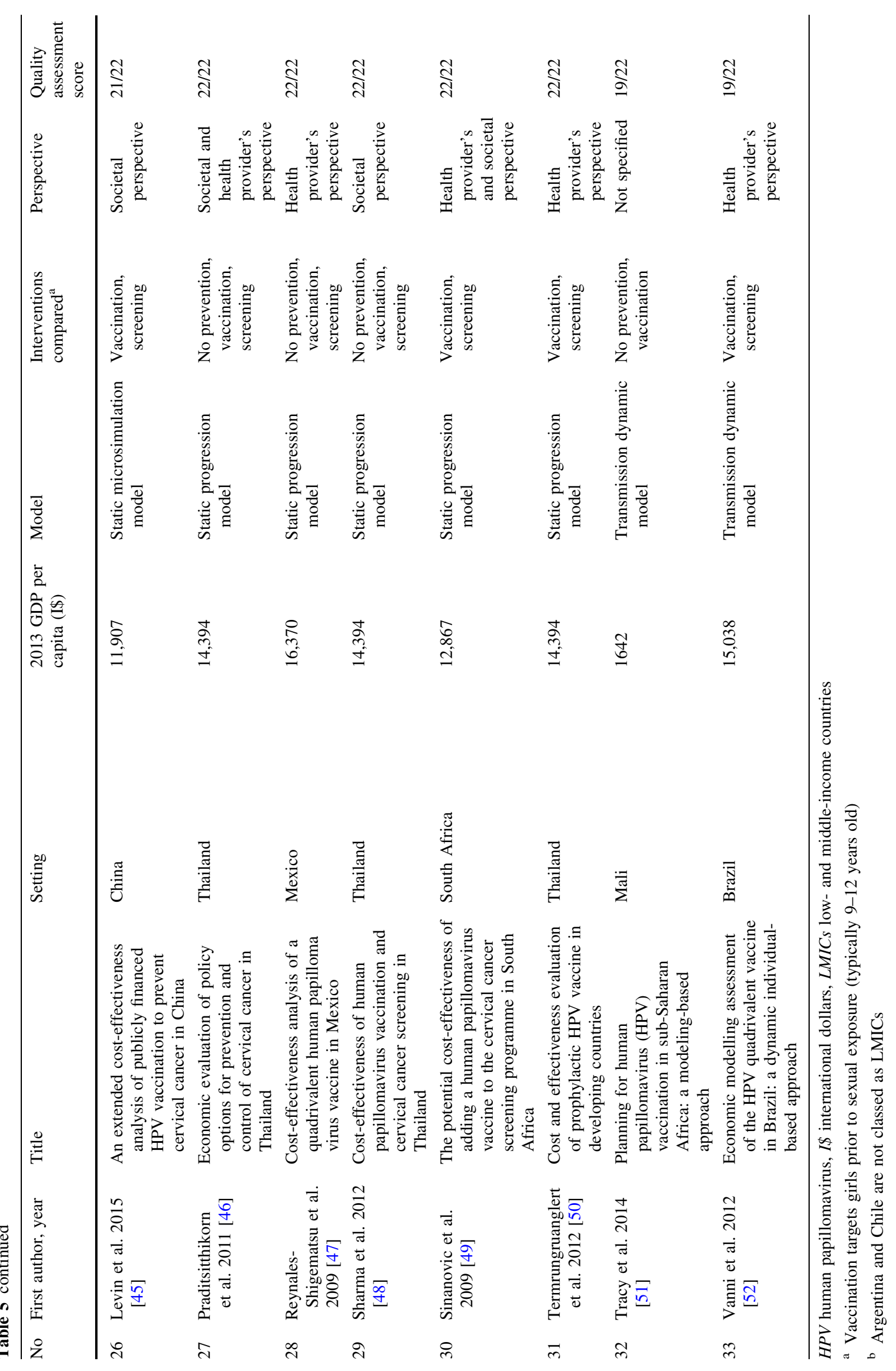




\section{References}

1. Globocan. GLOBOCAN 2012: Estimated Cancer Incidence, Mortality and Prevalence Worldwide in 2012. International Agency for Research on Cancer. 2012. http://globocan.iarc.fr/ Pages/fact_sheets_cancer.aspx. Accessed 26 Nov 2014.

2. WHO. Comprehensive Cervical Cancer: a guide to essential practice. Geneva: WHO 2014.

3. Bray F, Loos AH, McCarron P, Weiderpass E, Arbyn M, Moller $\mathrm{H}$, et al. Trends in cervical squamous cell carcinoma incidence in 13 European countries: changing risk and the effects of screening. Cancer Epidemiol Biomark Prev Publ Am Assoc Cancer Res Cosponsored Am Soc Prev Oncol. 2005;14(3):677-86. doi:10. 1158/1055-9965.epi-04-0569.

4. Ferko N, Postma M, Gallivan S, Kruzikas D, Drummond M. Evolution of the health economics of cervical cancer vaccination. Vaccine. 2008;26(Suppl 5):F3-15. doi:10.1016/j.vaccine.2008.02.004.

5. WHO. Human papillomavirus vaccines. WHO position paper. Weekly Epidemiological Record. 2009.

6. Jumaan AO, Ghanem S, Taher J, Braikat M, Al Awaidy S, Dbaibo GS. Prospects and challenges in the introduction of human papillomavirus vaccines in the extended Middle East and North Africa region. Vaccine. 2013;31 (Suppl 6):G58-64. doi:10. 1016/j.vaccine.2012.06.097.

7. Ekwunife O, Grote A, Mosch C, O’Mahony J, Lhachimi S. Assessing cost-effectiveness of HPV vaccines with decision analytic models: what are the distinct challenges of low- and middle-income countries? A protocol for a systematic review. Syst Rev. 2015;4(1):68.

8. Levin A, Wang SA, Levin C, Tsu V, Hutubessy R. Costs of introducing and delivering HPV vaccines in low and lower middle income countries: inputs for GAVI policy on introduction grant support to countries. PLoS One. 2014;9(6):e101114. doi:10. 1371/journal.pone.0101114.

9. Pang T. Vaccination in developing countries: problems, challenges and opportunities. Encyclopedia of life support systems (EOLSS): UNESCO-EOLSS

10. Hanson CM, Eckert L, Bloem P, Cernuschi T. Gavi HPV programs: application to implementation. Vaccines. 2015;3(2):408-19. doi:10.3390/vaccines3020408.

11. Bosch FX, Broker TR, Forman D, Moscicki AB, Gillison ML, Doorbar J, et al. Comprehensive control of human papillomavirus infections and related diseases. Vaccine. 2013;31(Suppl 7):H1-31. doi:10.1016/j.vaccine.2013.10.003.

12. Bruni L B-RL, Albero G, Aldea M, Serrano B, Valence S, Brotons M, Mena M, Cosano R, Muñoz J, Bosch FX, de Sanjosé S, Castellsagué X. ICO information centre on HPV and cancer (HPV Information Centre). Human Papillomavirus and Related Diseases Report: South Africa. 2015. Report No.: 2015-03-20.

13. ICO. Human Papillomavirus and Related Diseases Report: Nigeria. Barcelona: Institut Català d'Oncologia, Avda; 2014.

14. PAHO. Cervical cancer prevention and control programs: a rapid assessment in 12 countries of Latin America. Washington, D.C.: Pan American Health Organization; 2010.

15. Fesenfeld M, Hutubessy R, Jit M. Cost-effectiveness of human papillomavirus vaccination in low and middle income countries: a systematic review. Vaccine. 2013;31(37):3786-804. doi:10. 1016/j.vaccine.2013.06.060.

16. Lehtinen Ta NK. Cost-effectiveness of HPV-vaccination in medium or low income countries with high cervical cancer incidence-a systematic review. J Vaccin Vaccin. 2013. doi:10. 4172/2157-7560.1000172.

17. Jit M, Levin C, Brisson M, Levin A, Resch S, Berkhof J, et al. Economic analyses to support decisions about HPV vaccination in low- and middle-income countries: a consensus report and guide for analysts. BMC Med. 2013;11:23. doi:10.1186/17417015-11-23.

18. World-Bank. Country and Lending Groups. World Bank Group. 2015. http://data.worldbank.org/about/country-and-lendinggroups. Accessed 6 Jan 2015.

19. Husereau D, Drummond M, Petrou S, Carswell C, Moher D, Greenberg D, et al. Consolidated health economic evaluation reporting standards (CHEERS)-explanation and elaboration: a report of the ISPOR health economic evaluation publication guidelines good reporting practices task force. Value Health J Int Soc Pharmacoecon Outcomes Res. 2013;16(2):231-50. doi:10. 1016/j.jval.2013.02.002.

20. Aponte-Gonzalez J, Fajardo-Bernal L, Diaz J, Eslava-Schmalbach J, Gamboa O, Hay JW. Cost-effectiveness analysis of the bivalent and quadrivalent human papillomavirus vaccines from a societal perspective in Colombia. PloS One. 2013;8(11):e80639. doi:10.1371/journal.pone.0080639.

21. Berkhof J, Bogaards JA, Demirel E, Diaz M, Sharma M, Kim JJ. Cost-effectiveness of cervical cancer prevention in Central and Eastern Europe and Central Asia. Vaccine. 2013;31(Suppl 7):H71-9. doi:10.1016/j.vaccine.2013.04.086.

22. Campos NG, Kim JJ, Castle PE, Ortendahl JD, O'Shea M, Diaz M, et al. Health and economic impact of HPV 16/18 vaccination and cervical cancer screening in Eastern Africa. Int $\mathrm{J}$ Cancer. 2012;130(11):2672-84. doi:10.1002/ijc.26269.

23. Canfell K, Shi JF, Lew JB, Walker R, Zhao FH, Simonella L, et al. Prevention of cervical cancer in rural China: evaluation of HPV vaccination and primary HPV screening strategies. Vaccine. 2011;29(13):2487-94. doi:10.1016/j.vaccine.2010.12.085.

24. Colantonio L, Gomez JA, Demarteau N, Standaert B, PichonRiviere A, Augustovski F. Cost-effectiveness analysis of a cervical cancer vaccine in five Latin American countries. Vaccine. 2009;27(40):5519-29.

25. Diaz M, Kim JJ, Albero G, De Sanjose S, Clifford G, Bosch FX, et al. Health and economic impact of HPV 16 and 18 vaccination and cervical cancer screening in India. Br J Cancer. 2008;99(2):230-8.

26. Fonseca AJ, Ferreira LC, Neto GB. Cost-effectiveness of the vaccine against human papillomavirus in the Brazilian Amazon region. Revista da Associacao Medica Brasileira (1992). 2013;59(5):442-51. doi:10.1016/j.ramb.2013.03.004.

27. Ginsberg GM, Edejer TTT, Lauer JA, Sepulveda C. Screening, prevention and treatment of cervical cancer-a global and regional generalized cost-effectiveness analysis. Vaccine. 2009;27(43):6060-79.

28. Goldie SJ, Diaz M, Constenla D, Alvis N, Andrus JK, Kim SY. Mathematical models of cervical cancer prevention in Latin America and the Caribbean. Vaccine. 2008;26(SUPPL. 11):L59-72.

29. Goldie SJ, Diaz M, Kim SY, Levin CE, Van Minh H, Kim JJ. Mathematical models of cervical cancer prevention in the Asia Pacific region. Vaccine. 2008;26(Suppl. 12):M17-29.

30. Goldie SJ, Kim JJ, Kobus K, Goldhaber-Fiebert JD, Salomon J, O'Shea MK, et al. Cost-effectiveness of HPV 16, 18 vaccination in Brazil. Vaccine. 2007;25(33):6257-70. doi:10.1016/j.vaccine. 2007.05.058

31. Goldie SJ, Levin C, Mosqueira-Lovon NR, Ortendahl J, Kim J, O'Shea M, et al. Health and economic impact of human papillomavirus 16 and 18 vaccination of preadolescent girls and cervical cancer screening of adult women in Peru. Revista panamericana de salud publica Pan Am J Public Health. 2012;32(6):426-34.

32. Goldie SJ, O'Shea M, Campos NG, Diaz M, Sweet S, Kim SY. Health and economic outcomes of HPV 16,18 vaccination in 72 GAVI-eligible countries. Vaccine. 2008;26(32):4080-93.

33. Gutierrez-Aguado A. Cost-utility of the vaccine against the human papiloma virus in Peruvian women. Revista peruana de medicina experimental y salud publica. 2011;28(3):416-25. 
34. Gutierrez-Delgado C, Baez-Mendoza C, Gonzalez-Pier E, de la Rosa AP, Witlen R. Generalized cost-effectiveness of preventive interventions against cervical cancer in Mexican women: results of a Markov model from the public sector perspective. Salud Publica Mex. 2008;50(2):107-18.

35. Insinga RP, Dasbach EJ, Elbasha EH, Puig A, Reynales-Shigematsu LM. Cost-effectiveness of quadrivalent human papillomavirus (HPV) vaccination in Mexico: a transmission dynamic model-based evaluation. Vaccine. 2007;26(1):128-39. doi:10. 1016/j.vaccine.2007.10.056.

36. Jit M, Brisson M, Portnoy A, Hutubessy R. Cost-effectiveness of female human papillomavirus vaccination in 179 countries: a PRIME modelling study. Lancet Glob Health. 2014;2(7):e40614. doi:10.1016/s2214-109x(14)70237-2.

37. Kawai K, de Araujo GT, Fonseca M, Pillsbury M, Singhal PK. Estimated health and economic impact of quadrivalent HPV (types 6/11/16/18) vaccination in Brazil using a transmission dynamic model. BMC Infect Dis. 2012;12:250. doi:10.1186/ 1471-2334-12-250.

38. Khatibi M, Rasekh HR, Shahverdi Z, Jamshidi HR. Cost-effectiveness evaluation of quadrivalent human papilloma virus vaccine for HPV-related disease in Iran. Iran $\mathrm{J}$ Pharm Res. 2014;13(SUPPL):225-34.

39. Kiatpongsan S, Kim JJ. Costs and cost-effectiveness of 9-valent human papillomavirus (HPV) vaccination in two East African countries. PLoS One. 2014;9(9):e106836. doi:10.1371/journal. pone. 0106836 .

40. Kim JJ, Andres-Beck B, Goldie SJ. The value of including boys in an HPV vaccination programme: a cost-effectiveness analysis in a low-resource setting. Br J Cancer. 2007;97(9):1322-8. doi:10.1038/sj.bjc.6604023.

41. Kim JJ, Campos NG, O'Shea M, Diaz M, Mutyaba I. Modelbased impact and cost-effectiveness of cervical cancer prevention in sub-Saharan Africa. Vaccine. 2013;31(Suppl 5):F60-72. doi:10.1016/j.vaccine.2012.07.093.

42. Kim JJ, Kobus KE, Diaz M, O’Shea M, Van Minh H, Goldie SJ. Exploring the cost-effectiveness of HPV vaccination in Vietnam: insights for evidence-based cervical cancer prevention policy. Vaccine. 2008;26(32):4015-24. doi:10.1016/j.vaccine.2008.05.038.

43. Kim JJ, Sharma M, O'Shea M, Sweet S, Diaz M, Sancho-Garnier $\mathrm{H}$, et al. Model-based impact and cost-effectiveness of cervical cancer prevention in the Extended Middle East and North Africa (EMENA). Vaccine. 2013;31(Suppl 6):G65-77. doi:10.1016/j. vaccine.2012.06.096.

44. Kim SY, Sweet S, Chang J, Goldie SJ. Comparative evaluation of the potential impact of rotavirus versus HPV vaccination in GAVI-eligible countries: a preliminary analysis focused on the relative disease burden. BMC Infect Dis. 2011;11:174. doi:10. 1186/1471-2334-11-174.

45. Levin CE, Sharma M, Olson Z, Verguet S, Shi JF, Wang SM, et al. An extended cost-effectiveness analysis of publicly financed HPV vaccination to prevent cervical cancer in China. Vaccine. 2015; doi:10.1016/j.vaccine.2015.02.052.

46. Praditsitthikorn N, Teerawattananon Y, Tantivess S, Limwattananon S, Riewpaiboon A, Chichareon S, et al. Economic evaluation of policy options for prevention and control of cervical cancer in Thailand. PharmacoEconomics. 2011;29(9):781-806. doi:10.2165/11586560-000000000-00000.

47. Reynales-Shigematsu LM, Rodrigues ER, Lazcano-Ponce E. Cost-effectiveness analysis of a quadrivalent human papilloma virus vaccine in Mexico. Arch Med Res. 2009;40(6):503-13. doi:10.1016/j.arcmed.2009.08.004.

48. Sharma M, Ortendahl J, van der Ham E, Sy S, Kim JJ. Costeffectiveness of human papillomavirus vaccination and cervical cancer screening in Thailand. BJOG Int J Obstet Gynaecol. 2012;119(2):166-76. doi:10.1111/j.1471-0528.2011.02974.x.
49. Sinanovic E, Moodley J, Barone MA, Mall S, Cleary S, Harries J. The potential cost-effectiveness of adding a human papillomavirus vaccine to the cervical cancer screening programme in South Africa. Vaccine. 2009;27(44):6196-202. doi:10.1016/j.vaccine.2009.08.004.

50. Termrungruanglert $\mathrm{W}$, Havanond $\mathrm{P}$, Khemapech $\mathrm{N}$, Lertmaharit S, Pongpanich S, Khorprasert C, et al. Cost and effectiveness evaluation of prophylactic HPV vaccine in developing countries. Value Health J Int Soc Pharmacoecon Outcomes Res. 2012;15(1 Suppl):S29-34. doi:10.1016/j.jval.2011.11.007.

51. Tracy JK, Schluterman NH, Greene C, Sow SO, Gaff HD. Planning for human papillomavirus (HPV) vaccination in subSaharan Africa: a modeling-based approach. Vaccine. 2014;32(26):3316-22. doi:10.1016/j.vaccine.2014.03.067.

52. Vanni T, Mendes Luz P, Foss A, Mesa-Frias M, Legood R. Economic modelling assessment of the HPV quadrivalent vaccine in Brazil: a dynamic individual-based approach. Vaccine. 2012;30(32):4866-71. doi:10.1016/j.vaccine.2012.04.087.

53. Pitt C, Vassall A, Teerawattananon Y, Griffiths UK, Guinness L, Walker D, et al. Foreword: health economic evaluations in lowand middle-income countries: methodological issues and challenges for priority setting. Health Econ. 2016;25(Suppl 1):1-5. doi:10.1002/hec.3319.

54. Quentin W, Terris-Prestholt F, Changalucha J, Soteli S, Edmunds WJ, Hutubessy R, et al. Costs of delivering human papillomavirus vaccination to schoolgirls in Mwanza Region, Tanzania. BMC Med. 2012;10:137. doi:10.1186/1741-7015-10-137.

55. Levin CE, Van Minh H, Odaga J, Rout SS, Ngoc DN, Menezes L, et al. Delivery cost of human papillomavirus vaccination of young adolescent girls in Peru, Uganda and Viet Nam. Bull World Health Organ. 2013;91(8):585-92. doi:10.2471/blt.12.113837.

56. GAVI. Human papillomavirus vaccine support. The Vaccine Alliance. 2014. http://www.gavi.org/support/nvs/human-papillomavirus-vaccine-support/\#. Accessed 8 Dec 2014.

57. LaMontagne DS, Barge S, Le NT, Mugisha E, Penny ME, Gandhi $S$, et al. Human papillomavirus vaccine delivery strategies that achieved high coverage in low- and middle-income countries. Bull World Health Organ. 2011;89(11):821-830b. doi:10.2471/ blt.11.089862.

58. Fagot JP, Boutrelle A, Ricordeau P, Weill A, Allemand H. HPV vaccination in France: uptake, costs and issues for the National Health Insurance. Vaccine. 2011;29(19):3610-6. doi:10.1016/j. vaccine.2011.02.064.

59. Dorleans F, Giambi C, Dematte L, Cotter S, Stefanoff P, Mereckiene $\mathrm{J}$ et al. The current state of introduction of human papillomavirus vaccination into national immunisation schedules in Europe: first results of the VENICE2 2010 survey. Euro Surveill. 2010;15(47).

60. Varghese C, Carlos MC, Shin HR. Cancer burden and control in the Western pacific region: challenges and opportunities. Ann Glob Health. 2014;80(5):358-69. doi:10.1016/j.aogh.2014.09.015.

61. Claxton K. The irrelevance of inference: a decision-making approach to the stochastic evaluation of health care technologies. J Health Econ. 1999;18(3):341-64.

62. Koopmanschap MA, Stolk EA, Koolman X. Dear policy maker: have you made up your mind? A discrete choice experiment among policy makers and other health professionals. Int $\mathrm{J}$ Technol Assess Health Care. 2010;26(2):198-204. doi:10.1017/s0266462310000048.

63. Hoomans T, Severens JL. Economic evaluation of implementation strategies in health care. Implement Sci IS. 2014;9:168. doi:10.1186/s13012-014-0168-y.

64. Hoomans T, Ament AJ, Evers SM, Severens JL. Implementing guidelines into clinical practice: what is the value? J Eval Clin Pract. 2011;17(4):606-14. doi:10.1111/j.1365-2753.2010.01557.x.

65. Antai D. Rural-urban inequities in childhood immunisation in Nigeria: the role of community contexts. J Primary Health Care \& Fam Med 2011;3(1):238. doi:10.4102/phcfm.v3i1.238. 